\title{
Optimizing the Charge Transfer Process by Synthesizing NiO Microspheres on Ni Foam through Microwave-assisted Method
}

\author{
HAN Dan-Dan ${ }^{1}$, JING Xiao-Yan ${ }^{2}$, XU Peng-Cheng ${ }^{1}$, TAN Ao ${ }^{1}$, CHENG Zhen-Yu ${ }^{1}$ \\ (1. College of Chemistry and Pharmaceutical Engineering, Jilin Institute of Chemical Technology, Jilin 132022, China; 2. College of \\ Materials Science and Chemical Engineering, Harbin Engineering University, Harbin 150001, China)
}

\begin{abstract}
The porous nickel oxide microsphere on Ni foam was adopted to optimize the charge transfer process to improve electrochemical performance by a microwave-assisted method. Microstructure and morphologies of the resulting materials were investigated by X-ray diffraction, scanning electron microscope, transmission electron microscope. Results showed that the as-prepared $\mathrm{NiO}$ microspheres with nickel sulfate had average diameter of $\sim 2 \mu \mathrm{m}$. The ultrathin secondary nanoflakes composed of nanowire building blocks were interconnected with each other forming a highly open net-structure. Because of enhanced electron transfer capability, charge transfer resistances of the porous microsphere were reduced and the electrochemical performances were improved, the charge-discharge measurements tested at a discharge current of $0.5 \mathrm{~A} / \mathrm{g}$ showed higher rate specific capacitance ( $455 \mathrm{~F} / \mathrm{g})$. The impedance characterization illustrated lower electronic and ionic resistance of porous $\mathrm{NiO}$ due to its superior surface properties for enhanced electrode electrolyte contact during the faradaic redox reactions.
\end{abstract}

Key words: microwave-assisted synthesis; hierarchical nickel oxide; porous Nanoflake; electrochemical performance

As an energy storage device, an electrochemical capacitor (EC) or supercapacitor attracted great research interest from industry and academia because they are specified to be as important as batteries for future energy storage systems by the department of energy ${ }^{[1-2]}$. However, to be primary devices for power supply, supercapacitors must be developed further to improve their abilities to deliver high energy and power simultaneously. In this concern, many efforts have been devoted to the investigation of effective electrode. Therefore, various potential electrode materials including transition metal oxides, hydroxides, and electronically conducting polymer materials with high faradaic pseudocapacitance have been intensively investigated to obtain high energy density capacitors $^{[3-5]}$. Recently, extensive attention has been paid to investigate pseudocapacitive transition metal oxides (such as $\left.\mathrm{RuO}_{2}, \mathrm{MnO}_{2}, \mathrm{NiO}, \mathrm{Co}_{3} \mathrm{O}_{4}\right)^{[6-9]}$, which can obtain a much higher specific capacitance and energy density because they can supply different oxidation states for efficient redox reactions. Among them, nickel oxide has been attracting more interests due to its low cost and high theoretical specific capacitance or capacity ${ }^{[9-10]}$.

However, the good conductivity, low electrical resis- tance, and large contact area of the electrolytes and electrode materials are thus important to achieve a stable electrochemical performance for electrochemical capacitors. Among many reported strategies, in situ growth is an effective approach to design binder-free electrodes with many advantages. Up to date, the nickel oxide with the controllable morphologies and microstructures are prepared on the conductive substrates, which include 3D nickel foam, copper foam, titanium substrate, stainless-steel foil, and flexible carbon cloth $^{[11-12]}$. Moreover, several approaches have been demonstrated to construct the binder-free electrodes, such as hydrothermal synthesis, electrodeposition, chemical bath deposition, and pulsed laser deposition ${ }^{[13-14]}$. Various types of $\mathrm{NiO}$ binder-free electrodes which morphologies consist of nanosphere, 2D flakes and nanoflowers are fabricated. Despite the progress, the fabrication of self-supported hierarchical metal oxide spheres with porous architectures through a simple and fast process still remains a significant challenge. Therefore, developing a clean, cheap, and efficient heating progress to obtain well-defined 3-D structured nickel oxides and tuning their morphology, size and structure is an interesting work. Microwave mediated 
synthesis method, due to microwave-induced accelerated kinetics, improved nucleation rate, and reduction in the reaction time, has drawn large attention in the synthesis of oxide materials for supercapacitors application ${ }^{[15]}$.

Here we described a facile and reliable microwaveassisted route for the production of high-quality nickel oxide microspheres with extended nanoflakes which were grown on $\mathrm{Ni}$ foam. Electrochemical characteriza tions reveal that nickel oxide microspheres with the nanowire (NW-NiO) building blocks exhibit a high specific capacitance and excellent cycling stability, which may enable their practical applications as active electrode materials in energy storage devices.

\section{Experimental}

\subsection{Synthesis procedure}

All the chemicals were of analytical grade and were used without further purification. In a typical process, $6 \mathrm{mmol}$ of $\mathrm{NiSO}_{4} \cdot 6 \mathrm{H}_{2} \mathrm{O}$ was dissolved in $30 \mathrm{~mL}$ deionized water, and then $2.5 \mathrm{mmol}$ of $\left(\mathrm{NH}_{4}\right)_{2} \mathrm{SO}_{4}$ was added, the suspension was obtained by adding $9 \mathrm{~mL}(25 \mathrm{wt} \%)$ ammonia solution drop by drop into the beaker with stirring. Afterwards, the suspension was sealed in a flask and transferred to XH-300 UL ultrasonic synthesis machine (Xianghu Science and Technology Development Limited Company, Beijing). The nickel foam was immersed into the reaction solution subjected to microwave irradiation for $20 \mathrm{~min}$ at $200 \mathrm{~W}$, then turn to $100 \mathrm{~W}$ for $90 \mathrm{~min}$. After cooling to room temperature naturally, the products were collected by centrifugation, washed several times with deionized water and dried at $60^{\circ} \mathrm{C}$ for $24 \mathrm{~h}$ in vacuum. Finally, the samples were annealed at $300^{\circ} \mathrm{C}$ in air for $1 \mathrm{~h}$.

\subsection{Characterization}

$\mathrm{X}$-ray diffraction (XRD) measurement was examined on a Rigaku D/max TTR-III diffractometer using $\mathrm{Cu} \mathrm{K} \alpha$ radiation $(\lambda=0.15405 \mathrm{~nm})$. The morphologies of the samples were inspected on a scanning electron microscope (SEM, JSM-6480A, Japan Electronics). Transmission electron microscopy (TEM) micrographs were performed on a Tecnai $G^{2}$ F20 transmission electron microscope with a field emission gun operating at $200 \mathrm{kV}$.

\subsection{Electrochemical measurements}

The self-supported $\mathrm{NiO}$ nanoflowers were directly used as the working electrode. The electrochemical tests were conducted with a CHI 660E electrochemical workstation in an aqueous $\mathrm{KOH}$ electrolyte $(2.0 \mathrm{~mol} / \mathrm{L})$ with a three-electrode cell where $\mathrm{Pt}$ foil serves as the counter electrode and a saturated calomel electrode (SCE) were used as the counter and reference electrodes. The loaded weight of $\mathrm{NiO}$ nanoflower was controlled to be approxi- mately $5 \mathrm{mg} / \mathrm{cm}^{2}$. The EIS measurements were carried out in the frequency range from $100 \mathrm{kHz}$ to $0.01 \mathrm{~Hz}$ at open circuit potential with an $\mathrm{AC}$ perturbation of $5 \mathrm{mV}$.

\section{Results and discussion}

Fig. 1 shows the XRD patterns of the $\mathrm{NiO}$ sample, together with the $\mathrm{NiO}$ spheres scratched down from $\mathrm{Ni}$ foam for comparison. The XRD pattern confirms the existence of $\mathrm{NiO}$ and pure Ni phases. The diffraction peaks of $\mathrm{NiO}$ nanoflakes arrays observed at $37.2^{\circ}, 43.3^{\circ}, 62.8^{\circ}, 73.4^{\circ}$, and $79.4^{\circ}$ could be indexed as (111), (200), (220), (311), and (222) planes of the NiO phase (JCPDF 47-1049), whereas the diffraction peaks at about $45.0^{\circ}, 52.3^{\circ}$, and $76.9^{\circ}$ corresponding to the $\mathrm{Ni}$ foam, indicates that the $\mathrm{NiO}$ crystals have been successfully synthesized.

Fig. 2 shows the schematic diagram of preparation processes of NW-NiO microspheres. SEM images of the $\mathrm{NW}-\mathrm{NiO}$ microspheres prepared with nickel nitrate as nickel sources are shown in Fig. 3(a) and (b). Clearly, The $\mathrm{NiO}$ microspheres was comparatively uniformly dispersed or distributed on the surfaces of the Ni foam substrate. Fig. 3(b) shows agglomerated plush-like regular structures congregated on randomly arranged nanosized flakes with a diameter of $\sim 2 \mu \mathrm{m}$. A detailed observation revealed (as shown in the inset) that these plush microspheres consisted of straight and apical $\mathrm{NiO}$ nanoflakes with a wrinkled appearance, leaving few large channels for electrolyte diffusion. Interestingly, every porous ball forms a comparatively dense aggregate. The reason of the aggregation seems to be the effect of microwave, which creates "hot surface" on the initially formed $\mathrm{NiO}$ porous balls ${ }^{[16]}$.

To demonstrate the microstructures in further, TEM images of the NW-NiO microspheres with different magnifications are shown in Fig. 3(c). The NW-NiO sample shows one of the randomly arranged nanosize flakes for the microspheres. The flakes growth on both sides of the

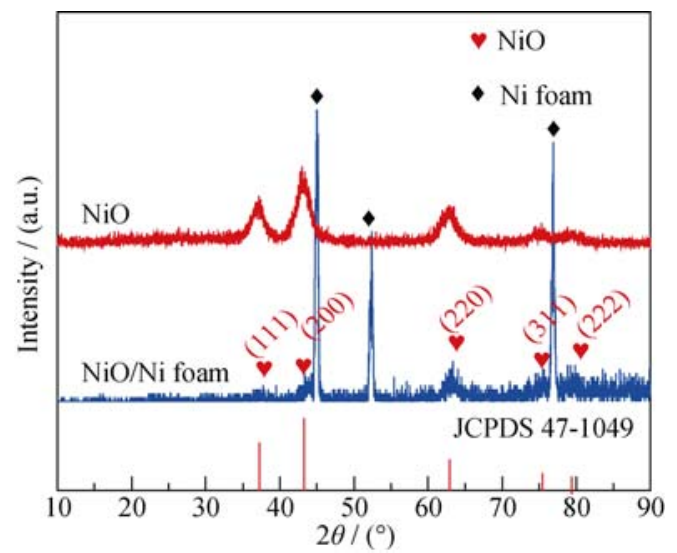

Fig. 1 XRD patterns of NW-NiO microspheres scratched down from $\mathrm{Ni}$ foam and $\mathrm{NiO} / \mathrm{Ni}$ sample 

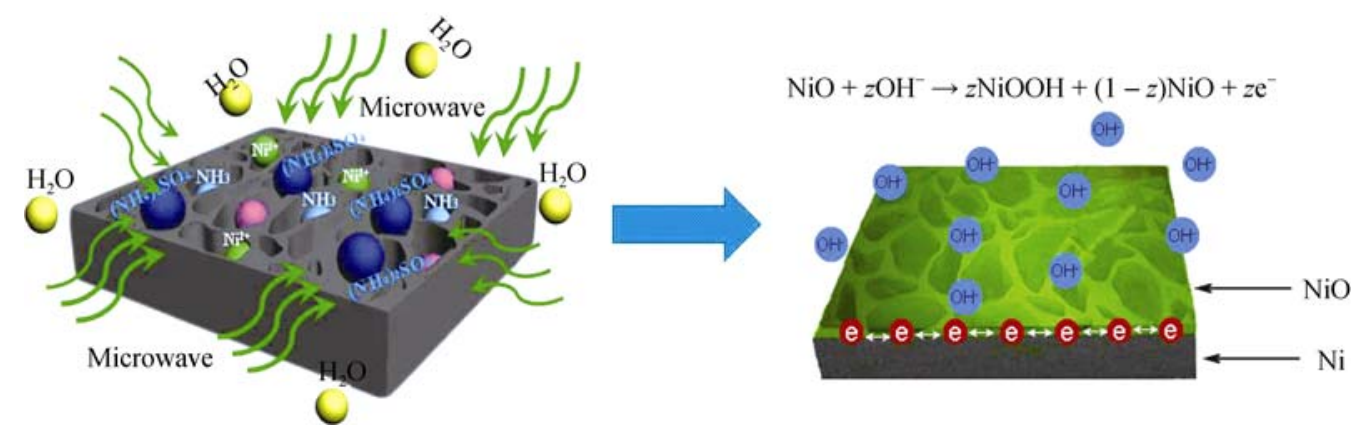

Fig. 2 Schematics of fabrication processes of NW-NiO microspheres
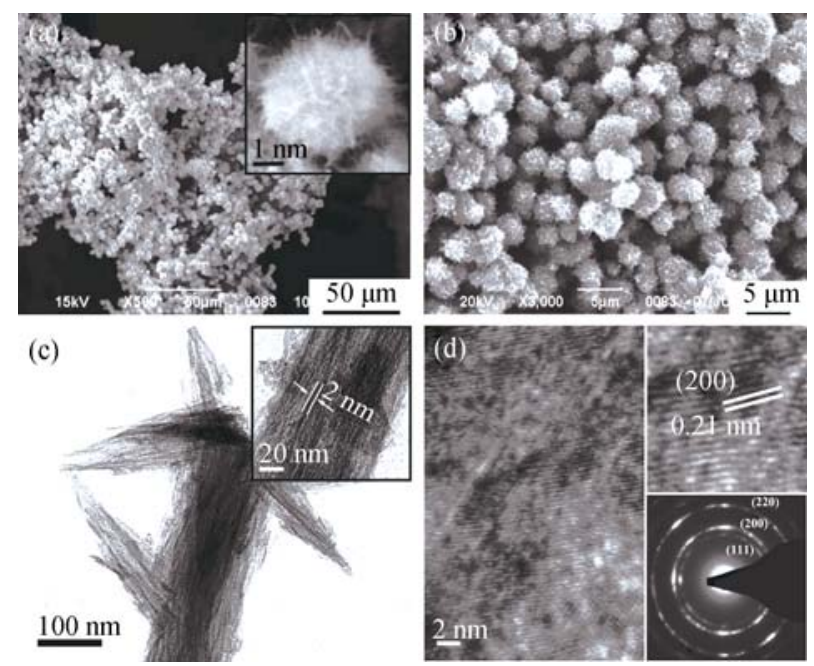

Fig. 3 SEM images of ( $a, b)$ NW-NiO microspheres (fine structure in inset), TEM images of (c) NW-NiO microspheres, HRTEM image and SAED pattern (d)

backbone are different from the conventional one ${ }^{[12,17-18]}$. A further insight into the surface structures of nanosized flakes. It is observed that it is composed of many $\mathrm{NiO}$ nanowires with a diameter of 1-5 nm. Furthermore, these building blocks of nanowires own rich mesopores due to the dehydration of the water.

The open structure is highly favorable for high-rate energy storage applications which require fast ion/electron transfer. Fig. 3(d) shows a high resolution TEM micrograph of the nanosheets, from which the lattice fringes can be clearly seen. The interplanar spacing in a representative crystallite is about $0.21 \mathrm{~nm}$, which is close to that of cubic $\mathrm{NiO}$ (200) planes. Besides, the SAED pattern detected from a sampling shows well-defined rings, revealing the polycrystalline characteristics.

To explore the potential applications in electrochemical energy storage, the NW-NiO samples were used to make supercapacitor electrodes and characterized with cyclic voltammetry, galvanostatic charge/discharge and impedance measurements. The $\mathrm{CV}$ responses of the $\mathrm{NW}-\mathrm{NiO}$ samples carried out at different scan rates $(5-50 \mathrm{mV} / \mathrm{s})$ in a fixed potential range of $0-0.45 \mathrm{~V}$ in aqueous $2 \mathrm{~mol} / \mathrm{L}$
$\mathrm{KOH}$ electrolyte are shown in Fig. 4(a). One typical redox couples characteristic of $\mathrm{NiO}$ is observed in the $\mathrm{CV}$ curve, which corresponds to the conversion between $\mathrm{NiOOH}$ and $\mathrm{NiO}$ as follows ${ }^{[19]}$ :

$$
\mathrm{NiO}=z \mathrm{OH}^{-} \rightarrow z \mathrm{NiOOH}+(1-z) \mathrm{NiO}+z \mathrm{e}^{-}
$$

The specific capacitance $\left(C_{\mathrm{s}}, \mathrm{F} / \mathrm{g}\right)$ values at different scan rates $(v, \mathrm{~V} / \mathrm{s})$ in the $\mathrm{CV}$ measurements were calculated using the following equation ${ }^{[20]}$ :

$$
C_{\mathrm{s}}=\left(\int \mathrm{Id} V\right) /(v m V)
$$

where $I$ is the current, $m$ is the mass of active material, $v$ is the potential scan rate and $\mathrm{d} V$ is the differential of potential. At potential scan rates of $5-50 \mathrm{mV} / \mathrm{s}$, the specific capacitance values for NW-NiO sample are found to be $900-678 \mathrm{~F} / \mathrm{g}$. The higher specific capacitance value and $\sim 25 \%$ capacitance loss with increase in the scan rate from 5 to $50 \mathrm{mV} / \mathrm{s}$ attribute to the regular gallery between the nanowires, which minimize resistance inside the pores and result in better capacitance retention at higher redox reaction conditions. The linear response of the peak current intensity with the scan rate (the insets of Fig. 4(b)) is also an indication of the fast electronic and ionic transport rates $^{[21]}$.

Results presented in Fig. 4(c) demonstrate the galvanostatic constant current charge/discharge curves at various current densities with an electrochemical window of $0-0.4 \mathrm{~V}$. According to the equation ${ }^{[22]}$ :

$$
C_{\mathrm{s}}=i /[m(\mathrm{~d} V / \mathrm{d} t)]
$$

specific capacitance value of NW-NiO has been calculated from the voltage-time measurements at applied current densities $(i)$, active mass of the sample $(m)$, and the discharge slope of the chrono-pentionmetric discharge curve $(\mathrm{d} V / \mathrm{d} t)$, using the equation.

Galvanostatic charge/discharge curves at various current densities illustrate that the charge curves of the NW-NiO electrode are almost symmetrical to the discharge counterparts, suggestive of high reversibility of the hybrid NW-NiO electrode. The specific capacitance of the NW-NiO sample obtained from the discharging curvesis calculated to be $455 \mathrm{~F} / \mathrm{g}$ at the current density of $0.5 \mathrm{~A} / \mathrm{g}$, 

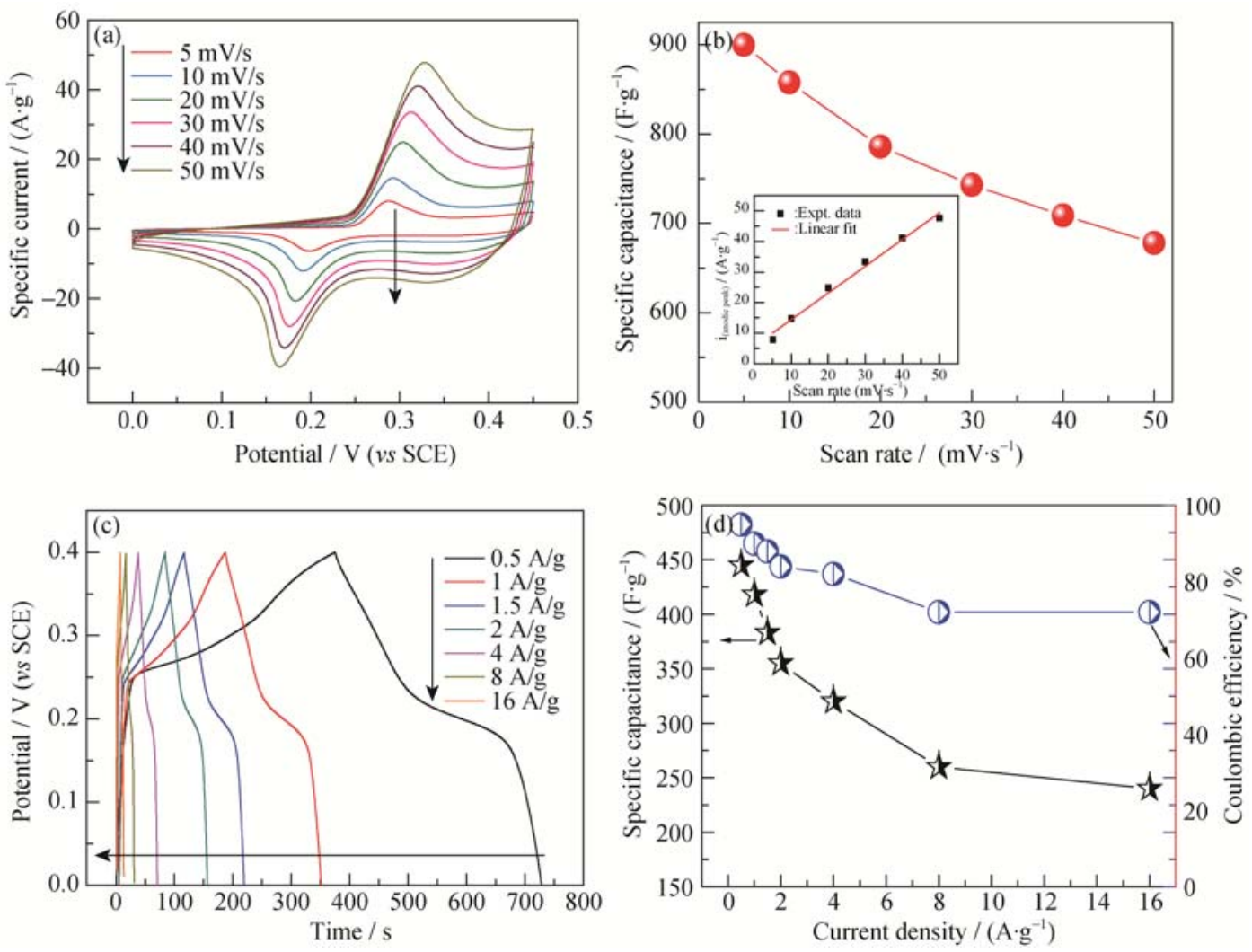

Fig. 4 Electrochemical properties of NW-NiO electroed

(a) CVs of hierachical NW-NiO electrode at the scan rates of 5, 10, 20,30, 40,50 mV/s, respectively; (b) Specific capacitance as a function of scan rate, the inset of (b) Shows the linearity of anodic current density with scan rate; (c) Charge and discharge curves of samples at different current density; (d) Specific capacitances and coulombic efficiency as function of discharge current densities of NW-NiO electrode

when the current density increases to $16 \mathrm{~A} / \mathrm{g}$, the specific capacitance is $240 \mathrm{~F} / \mathrm{g}$, corresponding to the coulombic efficiency is $95 \%, 90 \%, 88 \%, 84 \%, 82 \%, 72 \%$ and $72 \%$, respectively (Fig. 4(d)). It is known that the accessibility of $\mathrm{OH}^{-}$ions is a measurement of the faradaic reactions efficiency. Therefore, the $\mathrm{OH}^{-}$ions easily diffuse through the fibrous structure of $\mathrm{NiO}$ microspheres and access the inner space for more faradaic reactions to occur at lower current density. Even at the high current density $(16 \mathrm{~A} / \mathrm{g})$, the electrode also has high specific capacitance value, which is essentially attributable to better utilization of electroactive surface of the nanowires structure.

Impedance spectra of the NW-NiO supported on $\mathrm{Ni}$ foam was measured to further show the detailed characteristics of a capacitive electrode of as-obtained NW-NiO materials after 1000 cycles. Fig. 5 shows the Nyquist profiles of the NW-NiO sample before and after 1000 cycles. The impedance spectra are almost similar in shape, which consist of one semicircle at high frequency and followed by a straight line at the low frequency range. At the high frequency intercept of the real axis, indicating the electron conductivity of NW-NiO electrode. The charge transfer resistance $\left(R_{\mathrm{ct}}\right)$ and equivalent series resistance $\left(R_{\mathrm{s}}\right.$, including the active material, the current collector and the electrolyte) can be obtained by the fitting data. It can be seen that the solution resistance $\left(R_{\mathrm{s}}\right)$ is $0.42 \Omega$ and the $R_{\mathrm{ct}}$ of $\mathrm{NiO} / \mathrm{Ni}$ foam is $0.53 \Omega$ after 1000 cycles, the values are significantly smaller than the differently structured $\mathrm{NiO}$ electrodes reported in previous literature, the comparison of the solution resistance between the current study and other $\mathrm{NiO} / \mathrm{Ni}$ foam electrodes taken from the literature is shown in Table $1^{[23-26]}$. In addition, the diffusive resistance (Warburg impedance) of NW-NiO electrode is a little

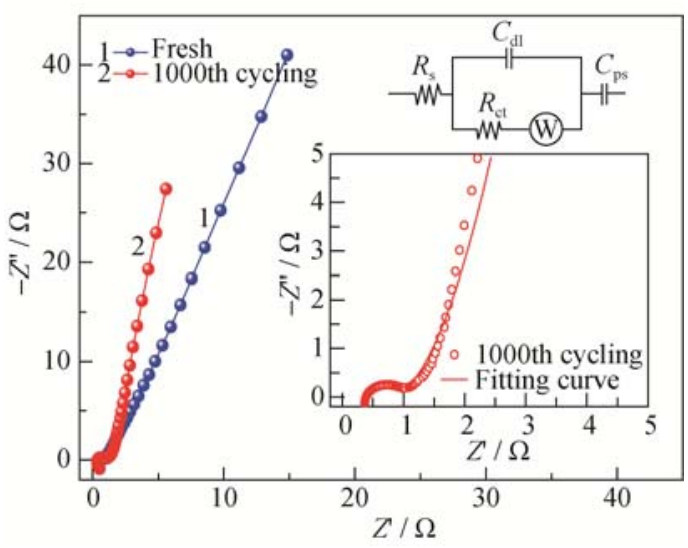

Fig. 5 Nyquist plots of experimental impedence data for NW-NiO electrode before and after 1000 charge-discharge cycles 
Table 1 Compared $\boldsymbol{R}_{\mathrm{ct}}$ for different structured NiO electrodes reported in previous literature

\begin{tabular}{lccc}
\hline \multicolumn{1}{c}{ Electrode structure } & Electrolyte & $R_{\mathrm{ct}} / \Omega$ & Reference \\
\hline Hierarchical NiO sphere/Ni & $\mathrm{KOH}\left(2 \mathrm{~mol} \cdot \mathrm{L}^{-1}\right)$ & 0.53 & This work \\
Porous NiO sheet/Ni & $\mathrm{KOH}\left(6 \mathrm{~mol} \cdot \mathrm{L}^{-1}\right)$ & $\approx 10$ & {$[23]$} \\
Co-doped NiO film/FTO & $\mathrm{KOH}\left(1 \mathrm{~mol} \cdot \mathrm{L}^{-1}\right)$ & 12.03 & {$[24]$} \\
$\mathrm{NiO} / \mathrm{CuO}$ nanoflower/ $\mathrm{Ni}$ & $\mathrm{KOH}\left(6 \mathrm{~mol} \cdot \mathrm{L}^{-1}\right)$ & $\approx 15$ & {$[25]$} \\
$\mathrm{NiO} / \mathrm{MWCNT}$ thin film/stainless steel & $\mathrm{KOH}\left(2 \mathrm{~mol} \cdot \mathrm{L}^{-1}\right)$ & 1.72 & {$[26]$} \\
\hline
\end{tabular}

higher after 1000 cycles in lower frequencies. This indicates that the capacitive behavior of NW-NiO is almost identical and suggests no appreciable change in structural during high rate cycling.

Long cyclic stability is one of the most important requirements for practical competence of supercapacitor devices. The cyclic specific capacitance performance of $\mathrm{NW}-\mathrm{NiO}$ sample for 1000 cycles at current density of $2.0 \mathrm{~A} / \mathrm{g}$ is presented in Fig. 6. It can be observed that the sample exhibits striking cyclic stability. After surface activation and minor pore opening (200 cycles), the capacitance gradually increases, the pseudo-capacitance reaches $360 \mathrm{~F} / \mathrm{g}, 3 \%$ increase of the first cycle value, after 1000 cycles, indicating its excellent pseudocapacitance retention capability. It is believed that the unique lower-dimensional nanowires building blocks of the $\mathrm{NiO}$ microstructures allow easy access of $\mathrm{OH}^{-}$to the $\mathrm{NiO}$ electrode surface, and there by offer high specific capacitance and less degradation during the cycle test.

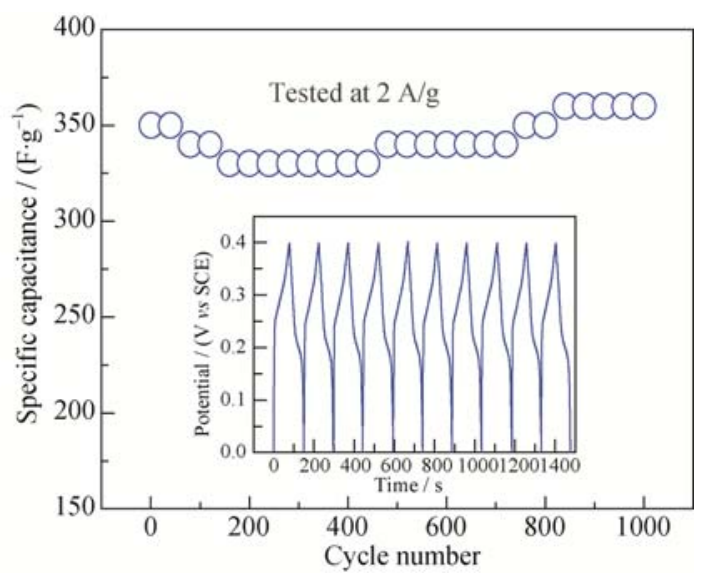

Fig. 6 Long cycle performance of $\mathrm{NiO}$ spheres measured at the current density of $2 \mathrm{~A} / \mathrm{g}$

\section{Conclusions}

In the present work, we have prepared plush-like nickel oxide microspheres with extended nanoflakes on nickel foam with strong adhesion for high-performance supercapacitors. The surface morphology, structure with different nickel sources and capacitive behaviors of the $\mathrm{NiO}$ spheres were well investigated. When the nickel source is nickel sulfate, the as-synthesized $\mathrm{NiO}$ sphere yields hierarchical structure with porous nanowires building blocks. Taking advantage of these characteristics, the NiO microstructures produced high specific capacitance and showed good retention for more than 1000 cycles in a cycling test.

\section{References:}

[1] SIMON P, GOGOTSI Y. Materials for electrochemical capacitors. Nat. Mater., 2008, 7(11): 845-854.

[2] WANG G, ZHANG L, ZHANG J. A review of electrode materials for electrochemical supercapacitors. Chem. Soc. Rev., 2012, 41(2): 797-828.

[3] ZHANG G Q, LOU X W. General solution growth of mesoporous $\mathrm{NiCO}_{2} \mathrm{O}_{4}$ nanosheets on various conductive substrates as high-performance electrodes for supercapacitors. Adv. Mater., 2013, 25(7): 975-979.

[4] ZHU G X, XI C Y, SHEN M Q, et al. Nanosheet-based hierarchical $\mathrm{Ni}_{2}\left(\mathrm{CO}_{3}\right)(\mathrm{OH})_{2}$ microspheres with meak crystallinity for high-performance supercapacitor. ACS Appl. Mater. Interfaces, 2014, 6(19): 17208-17214.

[5] WANG B, HE X Y, LI H P, et al. Optimizing the charge transfer process by designing $\mathrm{Co}_{3} \mathrm{O}_{4} @ \mathrm{PPy} @ \mathrm{MnO}_{2}$ ternary core-shell composite. J. Mater. Chem. A, 2014, 2(32): 12968-12973.

[6] HU C C, CHEN W C, CHANG K H. How to achieve maximum utilization of hydrous ruthenium oxide for supercapacitors. $J$. Electrochem. Soc., 2004, 151(2): A281-A290.

[7] WANG J G, KANG F Y, WEI B Q. Engineering of $\mathrm{MnO}_{2}$-based nanocomposites for high-performance supercapacitors. Prog. Mater. Sci., 2015, 74(1): 51-124.

[8] CHODANKAR N R, DUBAL D P, GUND G S, et al. Flexible all-solid-state $\mathrm{MnO}_{2}$ thin films based symmetric supercapacitors. Electrochim. Acta, 2015, 165(20): 338-347.

[9] YAN X Y, TONG X L, WANG J, et al. Synthesis of mesoporous $\mathrm{NiO}$ nanoflake array and its enhanced electrochemical performance for supercapacitor application. J. Alloys Compd., 2014, 593(25): 184-189.

[10] HU C C, CHEN J C, CHANG K H. Cathodic deposition of $\mathrm{Ni}(\mathrm{OH})_{2}$ and $\mathrm{Co}(\mathrm{OH})_{2}$ for asymmetric supercapacitors: importance of the electrochemical reversibility of redox couples. J. Power Sources, 2013, 221(1): 128-133.

[11] YANG W L, GAO Z, MA J, et al. Hierarchical $\mathrm{NiCo}_{2} \mathrm{O}_{4} @ \mathrm{NiO}$ core-shell heterostructured nanowire arrays on carbon cloth for a high-performance flexible all-solid-state electrochemical capacitor. 
J. Mater. Chem. A, 2014, 2(5): 1448-1457.

[12] LI Y H, ZHANG Y F, LI Y J, et al. Unveiling the dynamic capacitive storage mechanism of $\mathrm{Co}_{3} \mathrm{O}_{4} @ \mathrm{NiCo}_{2} \mathrm{O}_{4}$ hybrid nanoelectrodes for supercapacitor applications. Electrochim. Acta, 2014, 145(1): 177-184.

[13] CAI D P, HUANG H, WANG D D, et al. High-performance supercapacitor electrode based on the unique $\mathrm{ZnO} @ \mathrm{Co}_{3} \mathrm{O}_{4}$ core/shell hetero structures on nickel foam. ACS Appl. Mater. Interfaces, 2014, 6(18): 15905-15912.

[14] WU J B, LI Z G, HUANG X H, et al. Porous $\mathrm{Co}_{3} \mathrm{O}_{4} / \mathrm{NiO}$ core/shell nanowire array with enhanced catalytic activity for methanol electrooxidation. J. Power Sources, 2013, 224(1): 1-5.

[15] YANG M H, LEE K G, LEE S J, et al. Three dimensional expanded grapheme metal oxide film via solid state microwave irradiation for aqueous asymmetric supercapacitors. ACS Appl. Mater. Interfaces, 2015, 7(40): 22364-22371.

[16] HU X, GONG J, ZHANG L, et al. Continuous size tuning of monodisperse $\mathrm{ZnO}$ colloidal nanocrystal clusters by a microwave-polyol process and their application for humidity sensing. Adv. Mater., 2008, 20(24): 4845-4850.

[17] YAN H L, ZHANG D Y, XU J Y, et al. Solution growth of $\mathrm{NiO}$ nanosheets supported on Ni foam as high-performance electrodes for super capaci- tors. Nanoscale Res. Lett., 2014, 9: 424-430.

[18] QING X X, LIU S Q, HUANG K L, et al. Facile synthesis of $\mathrm{Co}_{3} \mathrm{O}_{4}$ nanoflowers grown on $\mathrm{Ni}$ foam with superior electrochemical performance. Electrochim. Acta, 2011, 56(14): 4985-4991.
[19] BAGHBANZADEH M, CARBONE L, COZZOLI P D, et al. Microwave-assisted synthesis of colloidal inorganic nanocrystals. Angew. Chem. Int. Ed., 2011, 50(48): 11312-11359.

[20] HSU H Y, CHANG K H, SALUNKHE R R, et al. Synthesis and characterization of mesoporous Ni-Co oxy-hydroxides for pseudocapacitor application. Electrochim. Acta, 2013, 94(1): 104-112.

[21] AMADE R, JOVER E, CAGLAR B, et al. Optimization of $\mathrm{MnO}_{2} /$ vertically aligned carbon nanotube composite for supercapacitor application. J. Power Sources, 2011, 196(13): 5779-5783.

[22] MOTASEMI F, AFZAL M T. A review on the microwave-assisted pyrolysis technique. Renewable Sustainable Energy Rev., 2013, 28: 317-330.

[23] YANG L, QIAN L, TIAN X Q, et al. Hierarchically porous nickel oxide nanosheets grown on nickel foam prepared by one-step in situ anodization for high-performance supercapacitors. Chem. Asian J., 2014, 9(6): 1579-1585.

[24] ZHANG J H, CAI G F, ZHOU D, et al. Co-doped NiO nanoflake array films with enhanced electro chromic properties. J. Mater. Chem. C, 2014, 2(34): 7013-7021.

[25] HUANG M, LI F, ZHANG Y X, et al. Hierarchical NiO nanoflake coated $\mathrm{CuO}$ flower core-shell nanostructures for supercapacitor. Ceram. Int., 2014, 40(4): 5533-5538.

[26] GUND G S, DUBAL D P, SHINDE S S, et al. Architectured morphologies of chemically prepared NiO/MWCNTs nanohybrid thin films for High Performance Supercapacitors. ACS Appl. Mater. Interfaces, 2014, 6(5): 3176-3188.

\title{
$\mathrm{NiO}$ 微球的微波辅助合成及电荷传导能力优化
}

\author{
韩丹丹 ${ }^{1}$, 景晓燕 ${ }^{2}$, 徐鹏程 ${ }^{1}$, 谭 奥 $^{1}$, 程振玉 ${ }^{1}$
}

(1. 吉林化工学院 化学与制药工程学院, 吉林 $132022 ; 2$. 哈尔滨工程大学 材料科学与化学工程学院, 哈尔滨 150001)

\begin{abstract}
摘 要: 为了优化电荷传导特性, 提高电极的电化学性能, 本工作采用微波辅助合成了分级多孔结构的氧化镍微球。通 过 XRD、SEM 和 TEM 对产物的形貌进行了表征。研究结果表明，开放多孔结构的氧化镍微球是由极薄纳米片自组 装而成, 以硫酸镍为镍源, 得到的氧化镍微球的粒径约为 $2 \mu \mathrm{m}$ 。作为超级电容器电极材料, 在电流密度为 $0.5 \mathrm{~A} / \mathrm{g}$ 时, 电极的比容量达到 $455 \mathrm{~F} / \mathrm{g}$, 由于 $\mathrm{NiO}$ 微球独特的多孔特性, 使电极表现出良好的阻抗特性, 为法拉第反应过程提供 了较多的活性反应点, 从而提高了电极的电容性能。
\end{abstract}

关 键 词: 微波辅助合成; 分级氧化镍; 多孔纳米片; 电化学性能 中图分类号: 0646

文献标识码: A 